\title{
Enfrentamentos e silenciamentos dos professores iniciantes na carreira universitária: um estudo com duas instituições públicas do Rio Grande do Sul
}

\author{
Facing and silence of Teachers initiatives in the university career: \\ a study with two public institutions of Rio Grande do Sul
}

\section{Desafíos y silencios de los profesores principiantes en la carrera universitaria: un estudio con dos instituciones públicas de Rio Grande do Sul}

\author{
ANDRESSA WIEBUSCH ${ }^{1}{ }^{1}$ \\ FERNANDA FÁtima COFFERRI (10 ${ }^{1}$ \\ GIONARA TAUCHEN $\odot^{2}$ \\ ${ }^{1}$ Pontifícia Universidade Católica do Rio Grande do Sul (PUCRS), Porto Alegre, RS, Brasil.
}

${ }^{2}$ Universidade Federal do Rio Grande - FURG, Rio Grande, RS, Brasil.

\begin{abstract}
RESUMO
Este artigo tem por objetivo analisar como professores iniciantes, atuantes em duas universidades públicas do Estado do Rio Grande do Sul (RS), vivenciaram o início da profissão, visando compreender os enfrentamentos e os silenciamentos produzidos no desempenho das atividades acadêmicas. A metodologia da pesquisa é qualitativa, sendo organizada por meio dos dados provenientes de entrevistas semiestruturadas realizadas com 14 professores iniciantes de duas universidades públicas a Universidade Federal do Rio Grande (FURG) e a Universidade Federal de Santa Maria (UFSM). Para a interpretação dos dados, optamos pela Análise de Conteúdo de Minayo (2010). Como resultados, evidenciamos que os professores sentem-se inseguros no desenvolvimento das atividades de ensino, pressionados pelas demandas da produção científica e inaptos para atuarem na gestão universitária. Para lidar com os cenários desafiadores, os professores desenvolvem estratégias de resiliência, como o desenvolvimento da autoestima, o diálogo com colegas e a reflexão sobre a prática docente. Concluímos que as universidades precisam incluir processos e programas de formação pedagógica nos planos de desenvolvimento institucional, aliando iniciativas de auto e ecoformação; integrar as ações de recepção e de adaptação dos professores entre as pró-reitorias e as unidades acadêmicas, bem como criar espaços formativos para o desenvolvimento de competências profissionais vinculadas ao desenvolvimento das atividades de ensino, pesquisa, extensão e gestão.
\end{abstract}

Palavras-chave: Professor Iniciante. Universidade. Formação Docente. Resiliência.

\begin{abstract}
This article aims to analyze how beginning professors working in two public universities from the State of Rio Grande do Sul (RS), experienced the beginning of the career, trying to understand the confrontations and the silencing produced in the performance of academic activities. The methodology of the research is qualitative and it was organized from a data collected from semi-structured interviews with 14 beginning professors of two public universities: The Federal University of Rio Grande (FURG) and The Federal University of Santa Maria (UFSM). For the data interpretation we decided by Minayo's Content Analysis (2010). As results we showed that professors feel insecure when developing teaching activities, pressured by the demands of scientific production and they also have the feeling of being unable to act in university management. To deal with all those challenging scenarios, professors developed a resilience strategy, such as developing self-esteem, the dialogue with colleagues and a thought about teaching practice. We conclude that universities need to include procedures and pedagogical training programs in their institutional development plans, combining self-development and eco-education initiatives; they also have to integrate the actions of reception and adaptation of professors between the pro-rectories and the academic units, as well as create training spaces for the development of professional skills linked to the development of teaching, research, extension and management activities.
\end{abstract}

Keywords: Beginning Professors. University. Teacher Training. Resilience. 


\begin{abstract}
RESUMEN
Este artículo tiene como objetivo analizar cómo los profesores principiantes, que actúan en dos universidades públicas del Estado de Rio Grande do Sul, vivenciaron el inicio de la profesión; buscando comprender los desafíos y silencios producidos en el desempeño de las actividades académicas. La metodología de investigación utilizada es cualitativa, organizada por medio de los datos provenientes de entrevistas semiestructuradas que se realizaron con 14 profesores principiantes de universidades públicas: la Universidade Federal do Rio Grande (FURG) y la Universidade Federal de Santa Maria (UFSM). Para la interpretación de los datos, se optó por el Análisis de contenido de Minayo (2010). Como resultados, se evidenció que los profesores se sienten inseguros en las actividades de enseñanza, presionados por las exigencias de producción científica e incapaces para actuar en la gestión universitaria. Para sobrellevar estos escenarios desafiantes, los profesores desarrollan estrategias de resiliencia, el incremento de la autoestima, el diálogo con los colegas y la reflexión sobre la práctica docente. Se concluye que las universidades necesitan incluir procesos y programas de formación pedagógica en los planes de desarrollo institucional, incluyendo iniciativas de auto y eco formación; integrar las acciones de recepción y de adaptación de los profesores entre las rectorías y las unidades académicas. Igualmente, crear espacios formativos para el desarrollo de competencias profesionales vinculadas a las actividades de enseñanza, investigación, extensión y gestión.
\end{abstract}

Palabras clave: Profesor Principiante. Universidad. Formación Docente. Resiliencia.

\section{CONSIDERAÇÕES INICIAIS}

A produção científica sobre a docência universitária caracteriza-se como um campo de investigação que se ocupa da natureza complexa dessa atividade, dos processos de trabalho e da saúde dos professores. Conforme estudos de Cunha (2009), Isaia e Bolzan (2004), Morosini (2000) e Zabalza (2004) têm sido produzidas reflexões, reiterando quão complexa é a docência e, ao mesmo tempo, pouco valorizada e reconhecida socialmente.

Pimenta e Anastasiou (2005, p. 142) afirmam que essa "relação profissional do professor com as instituições de ensino superior inicia-se pelo papel de docente". Iniciase com as atividades de ensino e, gradativamente, são inseridas múltiplas atividades na rotina do professor, em especial, as funções de pesquisa e as administrativas. Consequentemente, a atividade profissional do professor, segundo Tauchen e Fávero (2014, p. 31), “tornou-se mais complexa com as transformações culturais e com o surgimento de novas condições e exigências de trabalho: massificação da escolarização, novas tecnologias, programas institucionais, entre outros".

Nesse sentido, a profissionalização dos professores emerge em um cenário de "[...] dupla dimensão de desenvolvimento do estatuto social (profissionalismo) e do saber e competência como valores educativos (profissionalidade)" (MONTERO, 2005, p.91), pois precisam ser incluídos como aspirações prioritárias das políticas, dos sistemas e das instituições de ensino, visando à qualidade dos processos educativos. Zabalza (2004) aborda um aspecto fundamental que se refere ao exercício da docência e ao ato de ensinar, entendendo que este deveria ser o mais importante, porque nele se concentra a tarefa formativa da universidade.

Com base nesses referenciais, este estudo centra-se nas vivências dos professores iniciantes, por ser essa a fase em que os professores realizam a transição da condição de estudantes pós-graduados para docentes, de uma profissão para um processo de reprofissionalização e desenvolvimento de outras competências profissionais; aprendem e interiorizam novos modelos, normas, valores e condutas pedagógicas vinculadas à cultura docente e institucional na qual se integram, potencializando a interatividade profissional $^{1}$ (ISAIA et al., 2011).

Assim, o objetivo do estudo foi analisar como os professores iniciantes, atuantes em duas universidades públicas do Estado do Rio Grande do Sul (RS), vivenciam o início da profissão, visando compreender os enfrentamentos e os silenciamentos produzidos no desempenho das atividades acadêmicas.

\section{Abordagem Metodológica}

Este estudo é de natureza qualitativa e descritiva (CHIZZOTTI, 2006; LÜDKE e ANDRÉ, 1986), pois entendemos que as concepções do pesquisador e seus objetivos (CHIZZOTTI, 2006) estão vinculados ao estudo, bem como à subjetividade dos professores iniciantes. Os sujeitos da pesquisa foram oito professores iniciantes da Universidade Federal do Rio Grande (FURG) e seis da Universidade Federal de Santa Maria (UFSM). Os participantes foram selecionados com base nos seguintes critérios: estarem atuando há menos de três anos na instituição e não terem exercido a docência nesse nível de ensino.

Os dados foram coletados por meio de entrevistas semiestruturadas, gravadas e transcritas pelas pesquisa-

\footnotetext{
${ }^{1}$ Refere-se ao modo como os professores vêm conduzindo o processo de ensino. Cada vez mais, há uma abundância na formação e no exercício docente em estimular os professores a desempenharem a função de ensinar, estratégias didático-pedagógicas voltadas para o aprendizado ao longo da vida.
} 
doras e analisadas por meio da Análise de Conteúdo de Minayo (2010). Com base nas etapas de codificação: a) decomposição do material de análise em partes; b) distribuição das partes em categorias; c) descrição dos resultados da categorização; d) inferências dos resultados; e, por fim, e) interpretação dos resultados obtidos. Por meio desses procedimentos, emergiram as categorias de estudo que serão analisadas na sequência do artigo.

\section{Dilemas e ReAlizações do INÍCIO dA CARREIRA DOCENTE}

\subsection{Enfrentamentos e silenciamentos do cotidiano docente}

Nas universidades, o ensino é a principal função do trabalho de um professor. Porém, sabemos que a realidade está vinculada a compromissos que ultrapassam o "ensinar e aprender", incumbindo aos professores o desempenho de outras atividades. Nesse sentido, o desconhecimento e/ou o despreparo para conduzir as demandas educativas e institucionais, não vinculadas ao ensino, faz com que alguns professores, recém-chegados à universidade, vivenciem essa fase inicial com muitos enfrentamentos.

De acordo com Zabalza (2004), pensamos a docência como o trabalho do professor voltado ao ensino. Posto isso, é possível inferirmos que, enquanto os programas de pós-graduação não assumirem uma preparação para a docência, para além do estágio de docência obrigatório aos estudantes que são bolsistas, vamos continuar com professores pesquisadores que possuem conhecimentos técnicos, conhecimentos especializados e que, ao ingressarem na Educação Superior, se deparam com inúmeros desafios e enfrentamentos da profissão.

Sendo "o período de confrontação inicial do professor com as complexidades da situação profissional". (MARCELO GARCIA, 1999, p.28) No início, suscitam sentimento de insegurança frente aos alunos e à disciplina, falta de preparo pedagógico e de domínio do conteúdo da disciplina; além do desconhecimento dos processos de funcionamento administrativo da universidade, de gestão da pesquisa e da extensão.

Os pesquisadores Marcelo Garcia (2010), Cunha e Zanchet (2010) e Romanowski (2012), entre outros, têm produzido estudos reiterando os desafios que surgem aos professores iniciantes, tais como: dificuldades para a organização didática e para a construção do planejamento visando o ensino e a aprendizagem, aliar a ementa ao conteúdo e à carga horária da disciplina, como realizar a avaliação dos estudantes e ensinar conteúdos dos quais não têm conhecimento e a falta de apoio institucional no início da docência. As narrativas que seguem demonstram os enfrentamentos vivenciados no início da profissão:

\begin{abstract}
"Eu não tenho vergonha de dizer que muitas vezes eu cancelei aula porque eu não sabia. Eu preparava uma aula, mas não sabia o que ia falar, não tinha estudado. Muitos professores podem fazer um trabalhinho, mas eu pensava: não vou lá fazer ridículo. Sempre que cancelava aula, isso me incomodava. Eu sou professora, eu ganho para isso e ter que cancelar porque eu não estava pronta, não estava capacitada para falar daquele assunto." (P8)
\end{abstract}

Nessa narrativa, podemos perceber a ideia tradicional do domínio do conhecimento, como se o professor fosse e devesse ser capaz de dominar tudo que ensina, sendo ele o principal agente do processo didático, secundarizando a atividade dos estudantes. Além disso, não basta domínio dos conteúdos se não há uma preparação aos enfrentamentos da docência ancorada nas concepções de ensino e aprendizagem, na construção do conhecimento e nos sujeitos implicados neste processo.

O que requer afirmarmos que não basta apenas o conhecimento do campo ou área do saber, pois é necessário apropriar-se dos elementos que sustentam o trabalho pedagógico para potencializar a aprendizagem dos estudantes universitários. "O desafio dos professores está em compreender que a construção da docência envolve simultaneamente os conhecimentos pedagógicos e os conhecimentos da área específica". (BOLZAN; ISAIA; MACIEL, 2013, p. 55-56)

Outra questão evidenciada foi que o professor precisa estar preparado para a atuação docente, sendo, que a docência é complexa e a profissão exige um processo de formação permanente e continuada. Dois professores destacam mais desafios vivenciados:

\footnotetext{
"As disciplinas na minha pós-graduação foram muito direcionadas para uma área especifica. Quando cheguei, peguei três disciplinas. Tive que buscar conhecimentos para desenvolver essas disciplinas. Uma disciplina foi a parte experimental que trabalhei na pós-graduação, então tive um pouco mais de facilidade. Mas as outras duas iniciei do zero, pegando os livros e estudando. O mais complicado em termos de desafios é aliar a ementa ao conteúdo e tu tens que lidar com o tempo." (P9)

"O grande desafio era aprender o conteúdo antes de lecionar, porque me deparei com disciplina que não tinha conhecimento. Primeiro tinha que entender, para passar para um material em uma linguagem acessivel e objetiva, para apresentar para os alunos. Tive medo de não conseguir compreender o conteúdo a tempo de ensinar e aconteceu algumas vezes, só dei uma informada a respeito e não entrei a fundo. No outro semestre, consegui compreender e explicar em mais detalhes." (P10)
} 
Identificamos nessas narrativas a preocupação com a transposição didática dos conteúdos aos estudantes, com o modo de tornar os conhecimentos efetivamente transmissíveis e assimiláveis, a transformação do conhecimento científico em um conhecimento ensinável a partir de estratégias e formas de organização do trabalho pedagógico. Sendo assim, a transposição didática requer os conhecimentos da sua área e os conhecimentos pedagógicos para o processo de ensino e aprendizagem.

As dificuldades relatadas, em grande parte, decorrem da falta de formação e de preparação para o ensino universitário. A pesquisa e a produtividade científica são privilegiadas na pós-graduação, tornando o exercício docente confuso, pois "requer formação profissional para seu exercício: conhecimentos específicos para exercê-la adequadamente ou, no mínimo, a aquisição de habilidades e dos conhecimentos vinculados à atividade docente para melhorar sua qualidade". (VEIGA, 2008, p. 14)

Em relação ao trabalho pedagógico, os professores destacaram: a falta de preparação para a docência como reflexo da formação para a pesquisa, repercutindo na dificuldade com o planejamento das aulas; a gestão do tempo didático, do acadêmico e do tempo pessoal para administrar as múltiplas atividades da docência.

\subsection{Demandas da gestão}

Os professores iniciantes, que exercem tarefas no ensino, na pesquisa, na extensão e na gestão, vivenciam experiências e (re)configuram suas identidades através das subjetividades e interações compartilhadas. Conforme Zabalza (2004), atividades relacionadas à gestão universitária vêm sendo acrescidas à rotina e ao exercício docente. Essa afirmação confirma os dados das pesquisas em razão de que todos os professores que entrevistamos desenvolvem alguma atividade relacionada à gestão.

Alguns dos entrevistados são coordenadores de curso, membros do Conselho Universitário, avaliadores em comissões de bolsas para estudantes, quando não desempenham todas essas tarefas ao mesmo tempo:

\footnotetext{
"Trabalho em atividades de gestão, onde participo em algumas comissões de bolsas, financiamentos $e$ reuniões do colegiado do instituto." (P1)

"Sou responsável por este espaço. Eu que faço a gestão e coordeno o pessoal que trabalha aqui." (P2)

"Participo das comissões de bolsas da pós-graduação, do núcleo docente estruturante, das reuniões da pósgraduação, que são bem tensas pela questão da produtividade e das bolsas dos estudantes. [...] sou coordenadora do curso de graduação.” (P 7)
}

\begin{abstract}
"Entrei na coordenação por falta de opção. Sou adjunta, mas acabo sendo a coordenadora oficial; por isso ninguém queria pegar o cargo. Esse cargo exige mais reuniões fora daqui, coordenar toda a parte do ensino, procurar o professor que não está dando aula, atendimento a alunos e familiares [...] é bem puxado ser coordenadora, tem muita coisa pra fazer." (P8)
\end{abstract}

Por meio das narrativas, percebe-se que os professores iniciantes compõem um grupo atuante na gestão e administração universitária mesmo não tendo formação necessária para atuar na área. Desempenhar funções gestoras e administrativas na universidade, segundo Graef (2010, p. 3), "são acréscimos de responsabilidades de natureza gerencial ou de supervisão atribuídas ao servidor ocupante de cargo efetivo, tendo como referência a correlação de atribuições”.

Para a grande maioria dos professores, a formação inicial não contemplou conhecimentos e experiências de administração ou gestão institucional que, na maior parte dos casos, são aprendidas na vivência cotidiana do exercício da atividade. Por isso, a falta de conhecimentos referentes às funções de gestão e a própria cobrança, seja pessoal ou social, para cumprir as responsabilidades, podem desencadear situações frustrantes e estressoras que afetam o professor no desenvolvimento das outras atividades relacionadas ao ensino e à pesquisa. Ao desenvolver as funções administrativas, eles enfatizam que exigem maior tempo e dedicação, o que ocasiona na redução de tempo dedicado à pesquisa e à produção científica:

\footnotetext{
"Reduzi bastante meu ritmo de pesquisa depois que iniciei na docência universitária. Principalmente por ter um cargo administrativo que é de subcoordenador, acabo me envolvendo em questões administrativas que me roubam tempo da pesquisa e também procuro montar uma aula mais atraente para o aluno e fazer minhas aulas mais atrativas, assim, acabo perdendo mais tempo com isso e pesquisando menos. Procurei focar mais no ensino, participei do colegiado do curso desde o início, agora estou querendo entender da parte administrativa e talvez ir para a pós-graduação." (P11)
"O dilema do professor universitário é: enquanto as agências de fomento cada vez mais exigem que o professor seja um pesquisador, a gente tem a carga horária de ensino e o desejável seria que fizéssemos extensão. O professor que atua em ensino, pesquisa e extensão, tem que se dividir, além de atuar em funções administrativas, o que é um grande compli- cador." (P12)

Embora atuem na gestão e administração universitária, os professores iniciantes não recebem formação acadêmica 
ou profissional para tais atribuições. Sendo assim, é na prática, na vivência cotidiana e no relacionamento com os colegas mais experientes que eles são incluídos na gestão, o que constitui uma trajetória ajustada e reformulada frente às realidades educativas atuais.

Também evidenciamos que, ao assumir os cargos de gestão, o dilema inicial de conseguir articular o tripé universitário: ensino, pesquisa e extensão, pela inclusão do novo elemento, que é a gestão, visualiza-se como algo possível, pois, nessas atividades, o professor iniciante pode desincumbir-se das excessivas cargas horárias no ensino, equilibrando a atividade de pesquisa e extensão. Acreditamos que é preciso que o professor se organize para atender essas demandadas e para conseguir compreender esse espaço institucional no qual está inserido.

\subsection{Solidão profissional}

O modo como a universidade está organizada, em muitos casos, dificulta a execução de um trabalho compartilhado e articulado entre os professores. Não é de hoje que se ouvem relatos de que a docência é solitária. A dinâmica institucional, decorrente da reforma universitária da década de 1960, transformou as unidades universitárias em subunidades denominadas departamentos.

Com base no Art. 2, Decreto-Lei no 252, sendo "a menor fração da estrutura universitária para todos os efeitos de organização administrativa e didático-científica e de distribuição de pessoal" (BRASIL, 1967). Aliada a essa fragmentação, a dispersão dos estudantes, ao longo do curso, promovida pelo regime de créditos, dificultou a formação de uma comunidade acadêmica e, até mesmo, a comunicação entre os sujeitos, o que ainda permanece em nossa cultura.

Tendo em vista que a inserção no contexto universitário é uma etapa da profissão que requer acompanhamento formativo, é necessário um planejamento por parte das universidades no sentido de acolher e orientar a atuação dos professores na instituição, pois ainda vemos uma carência nesse suporte institucional. Como a pesquisa foi realizada em universidades públicas, vemos que essa é uma das demandas institucionais, como um dos entrevistados destacou:

\begin{abstract}
"Não tive muito apoio. Tive que dar uma disciplina que não tinha conhecimento nenhum, peguei material com um antigo professor substituto. Os professores que ministravam as disciplinas que estou ministrando não me ajudaram. Eu tive que correr atrás, pegar a ementa e preparar o material partindo do zero." (P13)
\end{abstract}

No contexto universitário, ao pesquisarmos acerca da cultura organizacional, percebemos que são raras as instituições que possuem programa de apoio para os professores iniciantes, o que pode gerar uma dificuldade para sua atuação uma vez que "o professor tem muitas tarefas individuais e pouco coletivas" (CUNHA, 2005, p.11). A ausência desse apoio institucional no enfrentamento dos desafios e das tensões da docência, evidencia a solidão pedagógica (ISAIA, 1992, 2003) dos professores iniciantes em relação às experiências no contexto universitário. As narrativas enfatizam isso:

\begin{abstract}
"Sinto-me despreparada, porque tenho turma com 80 alunos e na hora da aula soube que havia um aluno surdo na minha turma. Tem a questão dos indigenas e dos quilombolas, essa situação nos pede uma postura para entender que eles [estudantes] têm dificuldades. Fui descobrindo no decorrer do processo como fazer, sem nenhum tipo de instrução. Talvez se eu tivesse recebido uma orientação, pudesse ter conduzido de um modo diferente." (P4)

"Não há um apoio institucional em como preencher o sistema do portal do professor, como fazer o planejamento para o semestre." (P10)

"A gente não tem apoio institucional ou até tem, não sei desse apoio, não é algo divulgado, fiquei sabendo dois anos depois em uma conversa de corredor que tem uma pessoa que auxilia nisso.” (P11)

"Não há acompanhamento aos professores iniciantes, no meu departamento não existe nenhum tipo de orientação. São apresentadas as ementas das disciplinas, a bibliografia e temos de utilizar essa ementa estática. Precisamos fazer uma interpretação e estabelecer pela primeira vez a disciplina como a gente pretende ministrá-la. Esse é um dos principais desafios." (P12)
\end{abstract}

A partir das narrativas, percebemos o quanto os professores iniciantes estão desamparados, pois em nenhuma das instituições onde os eles atuam, há um programa de apoio institucional para suporte dos desafios diários que surgem na profissão, principalmente na fase iniciante. Também há a ausência de espaços sistemáticos de compartilhamento acerca dos fazeres e dos saberes da docência, tempos e espaços que possibilitem a discussão e compartilhamento das suas experiências e seus conhecimentos próprios à especificidade da profissão.

Como expressa Marcelo Garcia (2009, p.126), é fundamental "a criação de um espaço e um clima relacional adequado à reflexão colaborativa transformadora”. Nesse sentido, consideramos de extrema importância a criação de programas nas IES, bem como a proposição de políticas públicas para os professores iniciantes a fim de amenizar as dificuldades e os problemas existentes, além da organização de espaços que possibilitem o compartilhamento de saberes docentes. 


\subsection{Adaptação e resiliência docente}

O início da carreira universitária é repleto de tensões, ajustes, desequilíbrios, adequações, bem como de expectativas e conquistas. No momento inicial da docência, alguns professores reagem negativamente e, aos poucos, vão elaborando e adaptando-se à profissão e à sua própria rotina docente. Assim, identificamos a necessidade de reorganização diante dos desafios e conflitos evidenciados tanto na organização do trabalho pedagógico como nas atividades de gestão desempenhadas, buscando superar os desafios que vão surgindo na profissão.

A adaptação do professor é constante, desde o início até o final da carreira. São múltiplas exigências que perpassam essa atuação docente e, nesse cenário, é inevitável a adaptação aos contextos, emergindo competências profissionais para o ensino, pesquisa, extensão e gestão, mantendo estados de equilíbrio pessoal e controle dos fatores do estresse e do esgotamento profissional. As pesquisas de Scremin e Isaia (2011, p. 398), reiteram que a atuação docente na universidade é ampla e vai além das atividades de ensino:

[...] as funções docentes abarcam toda a tarefa educativa, ou seja, relacionam-se direta e principalmente com o processo de ensino-aprendizagem. Trazendo parte desta definição para o contexto da universidade foi possível confirmar a existência de professores exercendo mais de uma função docente.

As tarefas educativas compreendem desde os processos de organização do ensino, seleção de conteúdos, planejamento, acompanhamento e avaliação, até sua vinculação com o projeto pedagógico de curso, isto é, de forma mais ampla, as finalidades da Educação Superior. Por isso, em virtude da multidimensionalidade da docência, os professores promovem processos de adaptação.

Tais processos são tramados a partir de movimentos oscilatórios cujo dinamismo revela avanços e retrocessos, rupturas e resistências na produção de saberes e fazeres docentes. Desse modo, o processo constitutivo de ser professor parte de uma ambiência em que a possibilidade de resiliência docente permite construir algo novo a partir da trajetória pessoal e profissional de cada professor em particular e do grupo como um todo, pautado na autonomia docente. (ISAIA e BOLZAN, 2011, p. 188)

Diante dessa fase na vida pessoal e profissional, identificamos a docência como um percurso que visa à superação dos desafios. Com as múltiplas atividades e responsabilidades, esse exercício consiste em uma realização pessoal e também em uma conquista do seu espaço na instituição. Portanto, é necessária uma motivação para o desempenho das atividades, bem como no de processos de adaptação necessários ao exercício da docência.
A resiliência se enquadra numa perspectiva de desenvolvimento ao longo da vida, pois que se fundamenta num contínuo de ajustamentos face às dificuldades presentes no quotidiano dos sujeitos e à sua capacidade para enfrentar, saindo cada indivíduo desse confronto em patamares de desenvolvimento superiores (SOUSA, 2006, p. 41).

Nesse sentido, os professores iniciantes precisam de uma atenção especial, pois os primeiros anos da docência são fundamentais para o desenvolvimento profissional. Iniciar e permanecer na profissão torna-se desafiador perante as múltiplas exigências que perpassam a prática docente. Modos distintos de conduzir a vida pessoal e profissional são fundamentais, como afirmam LimongiFrança e Rodrigues (2014, p. 31), "a todo instante estamos fazendo movimentos de adaptação, ou seja, tentativa de nos ajustarmos às mais diferentes exigências, seja do ambiente externo, seja do mundo interno [...]".

A adaptação é necessária, pois as situações de estresse (positivas ou negativas), vivenciadas na fase da docência iniciante, demonstram a inevitabilidade de adaptações profissionais e pessoais. Para os professores iniciantes, múltiplos são os aspectos em que a adaptação é uma necessidade, como afirmam:

\begin{abstract}
"Você vai descobrindo no processo como fazer, sem nenhum tipo de instrução. Encontrar soluções alternativas para a falta de estrutura física é fundamental." (P4)
\end{abstract}

"Estas disciplinas que eu dou, eu nunca vi no meu curso, isso é muito complicado, porque no concurso pedia a formação que eu tinha, mas não era específica para atuar. Mas vou muito atrás, pesquiso, estudo, embora eu não tenha conhecimento prático nenhum daquilo, e é o que os alunos perguntam [...] e isso acontece com a maioria dos colegas." (P8)

"As experiencias de um semestre para o outro me ajudam, principalmente no conteúdo. Imaginei que uma metodologia de ensino fosse melhor para um determinado conteúdo e depois percebi que não, que talvez fosse melhor fazer de outro modo. Em relação aos conteúdos, mudei estratégias de ensino, porque percebi que o aluno aprende mais se utilizar outra metodologia, evolui de um semestre para o outro e nas formas de avaliação." (P11)

"As disciplinas que ministrei são disciplinas das quais tinha formação especifica e consegui organizá-las da maneira que achava melhor. Foi uma experiência tranquila em relação à docência, o problema foi o trabalho imenso, que é maior do que 40 horas. $O$ 
segundo ano de atuação é muito revelador, porque se consegue conciliar o tempo, porque é uma preparação secundária, uma reorganização do material. Já tenho experiência do que funciona e do que não funciona do tempo, do que deu para fazer na disciplina e o que não deu, e explorar outros tópicos." (P14)

Nesse cenário, os professores iniciantes desenvolvem a motivação não apenas nos momentos profissionais, mas também na dimensão pessoal da vida humana, visto que ela é fundamental para perceber as capacidades que possuem na promoção da autorrealização e da resiliência. Necessária à vida do professor, a resiliência é a capacidade de desenvolver estratégias para superar as adversidades cotidianas, envolvendo o cuidado de si e o autoconhecimento.

Praticar a resiliência é elementar para promover o bem-estar cotidiano, transformando o distress ${ }^{2}$, o stress "negativo" em eustress ${ }^{3}$, o stress "positivo". Auxilianos, ainda, a lidar com as incertezas e desenvolver os processos de adaptação essenciais à vida individual e coletiva. Por ser uma competência, permite enfrentar e até aprender com as circunstâncias desfavoráveis, pois envolve consciência, atitudes e habilidades ativadas nos processos de enfrentamento de problemas em todos os campos da vida.

Como se pode constatar nas narrativas dos entrevistados, os problemas da profissão são múltiplos e, ora são superados, ora são silenciados. Portanto, entende-se que a docência universitária é uma profissão em que se vivenciam contínuas situações de incertezas e alegrias. E é na reflexão coletiva sobre a docência, no desenvolvimento da autoestima e no desejo de transformação da educação que os momentos estressantes, de sobrecarga, de insegurança e esgotamento são superados, pois, as estratégias resilientes devem emergir nesses contextos incertos e desafiadores, redesenhando a profissão docente universitária.

\subsection{Reflexão sobre a prática docente}

O processo de interação e de mediação com os professores experientes também contribui muito para o principiante. A troca entre pares e interpares e o aprender com os mais experientes são elementos essenciais para a construção do ser professor. Diante dos desafios existentes e dos enfrentamentos que surgem na docência, "há possibilidade de reorganização e refinamento das ideias, concepções e saberes no e pelo grupo, favorecendo a construção compartilhada do conhecimento pedagógico" (BOLZAN, 2002, p. 14).

\footnotetext{
2 Caracteriza-se pela tensão, com o rompimento do equilíbrio orgânico dinâmico por excesso ou falta de esforço, incompatível com o tempo, realização e resultados. (AZEVEDO e KITAMURA, 2006, p. 140).

3 Caracteriza-se pela tensão com equilíbrio entre esforço, tempo, realização e resultados. (AZEVEDO e KITAMURA, 2006, p. 140).
}

Sendo a atividade reflexiva um elemento essencial para o desenvolvimento docente, questionamos os professores sobre como eles se reorganizam e/ou refletem acerca do planejamento e do trabalho pedagógico desenvolvido. As narrativas expressam que:

\begin{abstract}
"Ao longo do semestre vou fazendo anotações, ministro a aula e vejo os pontos que poderiam ser melhorados, pontos que poderiam ser agregados àqueles conteúdos. A cada aula vou tendo novas ideias para melhorar a disciplina." (P9)

"A avaliação de como foi a disciplina por parte dos alunos o departamento faz, tenho acesso a essa avaliação e vejo as sugestões dos alunos. Vou fazendo ao longo do semestre, uma avaliação das aulas e já faço uma previsão disso para o próximo semestre. Faço sempre uma autoavaliação, uma autocrítica das minhas aulas. " (P11)

“A reflexão é ao longo do semestre. Já estou pensando no que posso melhorar e conversando com alguns colegas, para direcionar alguns tópicos." (P13)
\end{abstract}

"Eu já tenho ideias de como modificar algumas aulas. Na última aula, o meu planejamento é pedir um feedback das aulas aos alunos." (P15)

As narrativas demonstram que eles percebem que precisam melhorar quando realizam uma consideração acerca das aulas ao longo e ao final do semestre, buscando qualificar a sua atuação docente "através de um trabalho de reflexividade crítica sobre as práticas e de (re)construção permanente de uma identidade pessoal" (NÓVOA, 1997, p. 25).

Para consolidar essa observação da e sobre a prática, ele precisa de um distanciamento para rever quais aulas ministradas foram exitosas e quais não tiveram êxito, buscando compreender a sua atuação, precisa refletir sobre "os processos de significação acerca do ser professor em termos de exigências e desafios implicados na docência", considerando "[...] a identificação das vivências formativas as quais expressam as singularidades dos processos de aprender e ensinar" (BOLZAN, 2014, p. 18). Essa ponderação se constitui em ação-reflexão-ação a partir das experiências vivenciadas na carreira universitária, quando o professor se coloca como protagonista, realizando uma autoavaliação, potencializando, deste modo, o processo de aprender a ser professor. De acordo com Bolzan (2006, p.378):

Ao refletir, [o professor] passa a pensar sobre situações passadas, estabelecendo relações com situações futuras do ensino que irá organizar. Esse processo de reflexão crítica feito individual ou coletivamente pode tornar o professor consciente dos modelos teórico e epistemológicos que se evidenciam na sua atuação profissional. 
Destacamos que, na reflexão, a tomada de consciência impulsiona o professor a ponderar acerca dos desafios e dos enfrentamentos que vivencia no ensinar e no aprender no contexto universitário. Nesse sentido, consideramos que a questão a ser pensada é sobre como estes elementos têm potencializado a aprendizagem da docência, sendo que as experiências formativas dos professores se constituem como suporte para reorganização do trabalho pedagógico.

\subsection{Bem-estar e autorrealização docente}

As reflexões tecidas nas seções acima apresentam que o bem-estar docente está presente na docência iniciante, bem como o mal-estar docente. Jesus (2002) afirma que o bem-estar e o mal-estar docente são duas faces da mesma moeda. A profissão é de natureza complexa: pode trazer felicidade, na qual o envolvimento pessoal é correspondido. Nos professores entrevistados, há muitos indícios de satisfação e contentamento com e na docência universitária:

"Eu adoro dar aula, valorizo muito o meu emprego [...] não me vejo fazendo outra coisa. Por mais que olhe para o contexto geral, pondere sobre 'o que me trouxe aqui?' Por pior que seja o contexto, nunca termino a aula dizendo 'estou infeliz'. A endorfina da aula e da pesquisa me faz muito bem." (P6)

"Não consigo me pensar trabalhando em outro lugar. Gosto muito do ambiente da universidade [...] é muito gratificante ser professora. Ao longo do curso, você participa da mudança da vida das pessoas e isso é muito bom, ver o aluno passar pela faculdade, se formar e fazer parte disso." (P8)

"Quando a gente entra na carreira docente, sente prazer em ensinar aos alunos e a gente vê que eles estão aprendendo. Para mim, é o principal na carreira, entre todos os pilares que a gente tem de trabalho, ensinar o aluno é fundamental. Todo dia, aprendemos uma coisa nova com os alunos, com os colegas de departamento, com a vivência na carreira." (P9)

"O gosto pela docência começou na graduação, me sinto muito feliz com a profissão que eu escolhi." (P10)

A partir dos depoimentos, notamos que os sentimentos de satisfação, autorrealização e prazer na docência são os alicerces produzidos individualmente ou coletivamente por eles. E que, segundo Isaia (2006) são considerados elementos dinamizadores da atividade educativa dos professores por representarem vivências afetivas de caráter apreciativo, condicionando a atitude valorativa dos educadores frente ao que é importante na vida pessoal e profissional já que envolvem uma dinâmica entre as experiências, competências e expectativas próprias a cada um, integrando o sentir, o pensar e o agir.

Assim, ao longo dos relatos expostos nesta pesquisa, notamos que mal-estar e bem-estar docente andam "lado a lado", ora são vivenciados momentos de alegria, ora a profissão pode transformar-se num vínculo desgastante em que a personalidade e a autoestima fiquem afetadas. O que se difere nesse processo é o modo como cada um resiste ou não às adversidades, como vivencia à docência e como organiza sua rotina de trabalho.

Têm professores que desenvolvem estratégias de enfrentamento de controle e/ou luta, referentes à autorrealização, valorização do próprio trabalho e motivação pessoal. Outros optam por estratégias evasivas, como a fuga e/ou esquiva, reportando-se ao afastamento e à negação ou ainda silenciando determinadas situações. Ambas as estratégias desencadeadas articulam o incremento da resiliência, visto que são atitudes que almejam evitar a sobrecarga de trabalho e os conflitos pessoais com os colegas. Portanto, os sujeitos da pesquisa mencionaram a autorrealização, valorização do próprio trabalho e motivação pessoal como sentimentos fundamentais às vivências da profissão.

\section{Considerações Finais}

Por meio do estudo realizado compreendemos que, ao ingressarem na Educação Superior, os professores deparam-se com múltiplos desafios envolvendo os processos de adaptação à organização institucional, desde as questões do ensino até a gestão da pesquisa, dos diferentes grupos e formas de interação.

No que se refere ao ensino, percebemos que não basta a pós-graduação para ingressar na carreira docente. É importante formação continuada e em serviço, visando tempos e espaços formativos para a problematização e socialização de conhecimentos pedagógicos da profissão.

Quanto às demandas da atividade docente, ele é desafiado a integrar ensino, pesquisa e extensão, bem como a gestão, evidenciando a necessidade de apoio institucional para instrumentalizar essa articulação, pois o seu compromisso prioritário na universidade é com a atividade de ensino. Nesse sentido, o professor iniciante expressa o conhecimento superficial sobre a cultura universitária decorrente da sua percepção como estudante.

É por meio da experiência cotidiana da docência e das múltiplas interações em diferentes espaços e atividades, que passa a (re)organizar seus saberes, concepções e competências. Cabe destacar, ainda, que os participantes da pesquisa expressam que se sentem pressionados pelas demandas da pesquisa e da produção científica e despreparados para atuarem na gestão universitária. 
Em relação à solidão profissional, identificamos o desamparo dos professores iniciantes frente aos desafios e enfrentamentos vivenciados na universidade, bem como falta um apoio institucional. Contudo, os entrevistados produzem estratégias de resiliência indispensáveis à adaptação às realidades vivenciadas. Por vezes, são os silêncios, por outras, as trocas de experiências, expressando que a fase inicial da docência universitária é um transcurso (re)criativo, resiliente e aprendente da profissão professor.

Ao refletirmos sobre a formação do professor universitário, são perceptíveis as necessidades de atividades formativas e a responsabilidade institucional pela criação de um programa de inserção à docência, visando apoio e acolhida ao professor iniciante para que possa conhecer a gestão administrativa e pedagógica da instituição, bem como compreender o trabalho docente na universidade, fortalecendo o processo de (re)profissionalização.

Assim, compreender a docência universitária como profissão implica considerar a complexidade das atividades e funções envolvidas, pois se trata de uma profissão de natureza social cuja efetivação mobiliza uma série de habilidades e competências que podem ser desenvolvidas, aperfeiçoadas e ampliadas por meio dos diferentes processos formativos. Nesse contexto, a discussão sobre a formação docente e o professor iniciante na Educação Superior é um campo aberto e profícuo para a realização de mais estudos e reflexões que venham a contribuir para a superação dos desafios vivenciados.

\section{REFERÊNCIAS}

AZEVEDO, V. A. Z.; KITAMURA S. Stress, Trabalho e Qualidade de Vida. In: VILARTA, Roberto et al. (org.). Qualidade de Vida e Fadiga Institucional. Campinas: IPES Editorial, 2006. p. 137-150.

BOLZAN, D. P. V. Formação de professores: compartilhando e reconstruindo conhecimentos. Porto Alegre: Mediação, 2002.

BOLZAN, D. P. V. Redes de relações docentes. In: MOROSINI, M. Enciclopédia de Pedagogia Universitária. Brasília: INEP, 2006. p. 381. Glossário, v. 2.

BOLZAN, D. P. V. Aprendizagem da Docência: processos formativos de estudantes e formadores da educação superior. Relatório Parcial do Projeto de Pesquisa no 032835. Centro de Educação, Universidade Federal de Santa Maria (UFSM), 2014. https://doi.org/10.20873/uft.2525-4863.2018v3n3p949

BOLZAN. D. P. V.; ISAIA. S.; MACIEL, A. M. R. Formação de professores: a construção da docência e da atividade pedagógica na Educação Superior. Revista Diálogo Educacional, Curitiba, v. 13, n. 38, p. 49-68, jan./abr. 2013. https://doi.org/10.7213/dialogo.educ.7625
BRASIL. Decreto-Lei no 252, de 28 de fevereiro de 1967. Estabelece normas complementares ao Decreto-Lei no $\mathbf{5 3}$, de 18 de novembro de 1966, e dá outras providências. Diário Oficial da União, Brasília: DF, 1967. Disponível em: https:// www2.camara.leg.br/legin/fed/declei/1960-1969/decretolei-252-28-fevereiro-1967-376151-publicacaooriginal-1-pe. html. Acesso em: 10 fev. 2018. https://doi.org/10.21680/19811802.2018v56n47id14009

CHIZZOTTI, A. Pesquisa qualitativa em ciências humanas e sociais. Petrópolis: Vozes, 2006.

CUNHA, M. I. O professor universitário na transição de paradigmas. 2. ed. Araraquara: Junqueira \& Marin, 2005.

CUNHA, M. I. O lugar da formação do professor universitário: o espaço da pós-graduação em educação em questão. Revista Diálogo Educacional (PUCPR), Curitiba, v. 9, p. 81-90, 2009. https://doi.org/10.7213/rde. v9i26.3664

CUNHA, M. I.; ZANCHET, B. M. B. A. A Problemática dos Professores Iniciantes: Tendência e Prática Investigativa no Espaço Universitário. Educação, Porto Alegre, v. 33, n. 3, p. 189-197, set./dez. 2010. Disponível em: http:// revistaseletronicas. Pucrs.br/ojs/index.php/faced/article/ view/6999/5717. Acesso em: 18 de jan. 2018.

GRAEF, A. Cargos em Comissão e Funções de Confiança: diferenças conceituais e práticas. Processo de Revisão do Estatuto e do Regimento Geral. Universidade Federal de Uberlândia. 2010. Disponível em: http://www0.ufu.br/ documentos/legislacao/Regimento_Geral_da_UFU.pdf. Acesso em: fev. 2018. https://doi.org/10.14295/2596-2221. xviceel.2018.202

ISAIA, S. M. A. Repercussão dos sentimentos e das cognições no fazer pedagógico de professores de $3^{\circ}$ e $4^{\circ}$ graus: produção de conhecimento e qualidade de ensino. Tese de Doutorado. Universidade Federal do Rio Grande do Sul, 1992.

ISAIA, S. M. A. Formação do professor de ensino superior: tramas na tessitura. In: MOROSINI, M. (org.). Enciclopédia de Pedagogia Universitária. Porto Alegre: FAPERGS/RIES, p. 241-251,2003. https://doi.org/10.29289/259453942018v2 $8 \mathrm{~s} 1059$

ISAIA, S. M. A.; BOLZAN, D. P. V. Formação do professor do ensino superior: um processo que se aprende? Educação (UFSM), Santa Maria, v. 29, n. 2, p. 121-133,2004.

ISAIA, S. M. A. Sentimento docente. Formação Docente e Educação Superior. In: MOROSINI, Marilia. Enciclopédia de Pedagogia Universitária. Brasília: INEP, 2006. Glossário, v. 2.

ISAIA, S. M. A.; MACIEL, A. M. R.; BOLZAN, D. P V. Pedagogia Universitária: desafios da entrada na carreira docente. Educação (UFSM), Santa Maria, v. 36, p. 425-440, 2011. https://doi.org/10.5902/198464442978 
ISAIA, S. M. A. BOLZAN; V. D. P. Tessituras formativas: articulação entre movimentos da docência e da aprendizagem docente. In: ISAIA, S. (org.). Qualidade da Educação Superior: a universidade como lugar de formação. Porto Alegre: EDIPUCRS, v. 2, p. 187-200, 2011. https://doi. org/10.26512/lc.v14i26.3424

JESUS, S. N. Perspectivas para o bem-estar docente. Lisboa: Cadernos do Centro de Recursos, 2002.

LIMONGI-FRANÇA, A. C.; RODRIGUES, A. L. Stress e trabalho: uma abordagem psicossomática. São Paulo: Atlas, 2014.

LÜDKE, M. ANDRÉ, M. E. D. A. Pesquisa em educação: abordagens qualitativas. São Paulo: EPU, 1986.

MARCELO GARCIA, C. Formação de professores: para uma mudança educativa. Porto: Porto Editora, 1999.

MARCELO GARCIA, C. El professorado principiante: inserción de la docencia. Barcelona: Ediciones Octaedro, 2009.

MARCELO GARCIA, C. O professor iniciante, a prática pedagógica e o sentido da experiência. Revista brasileira de pesquisa sobre formação docente, Belo Horizonte, Autêntica, v. 02, n. 03, p. 11-49, ago./dez. 2010.

MINAYO, M. C. S. (org.) Pesquisa social: teoria, método e criatividade. 29. ed. Petrópolis: Vozes, 2010.

MONTERO, L. A construção do conhecimento profissional docente. Lisboa: Instituto Piaget, 2005.

MOROSINI, M. C. Docência universitária e os desafios da realidade nacional. In: MOROSINI, M. C. (org.). Professor do ensino superior: identidade, docência e formação. Brasília: Instituto Nacional de Estudos e Pesquisas Educacionais, 2000. https://doi.org/10.14507/epaa.v22. 1516

NÓVOA, A. Os professores e sua formação. Lisboa: Dom Quixote, 1997.

PIMENTA; S. G.; ANASTASIOU, L. Docência no Ensino Superior. 2. ed. São Paulo: Cortez, 2005.

ROMANOWSKI, J. P. Professores principiantes no Brasil: questões atuais. In: CONGRESSO INTERNACIONAL SOBRE PROFESSORADO PRINCIPIANTE E INSERCIÓN PROFESSIONAL A LA DOCENCIA, III., Santiago do Chile, 2012.

SCREMIN, G.; ISAIA, S. M. A. Qualidade e funções docentes. In: FRANCO, M. E.; MOROSINI, M. (org.). Qualidade da educação Superior: dimensões e indicadores. 1ed. Porto Alegre: EDIPUCRS, 2011. p. 396-411. v. 4. https:// doi.org/10.4013/edu.2012.161.03

SOUSA, C. Educação para a Resiliência. Tavira: Ponto Pinta, 2006.
TAUCHEN, G.; FÁVERO, A. A. Docência e Gestão da Profissionalização na Educação Superior. In: TAUCHEN, G.; BORGES, D. S. (org.). Docência e Políticas na Educação Superior. Curitiba: Editora CRV, 2014. p. 29-40. v. 1. https:// doi.org/10.24824/978854440173.6

VEIGA, I. P. A. Trajetória profissional de docentes universitários: um estudo no campo da saúde. In: ISAIA, S. M. A.; BOLZAN, D. P. V. (org.). Pedagogia universitária e desenvolvimento profissional docente. Porto Alegre: EdiPUCRS, 2008. v. 4. Série Ries/PROMEX. https://doi.org/ 10.11606/t.22.2018.tde-28032018-155822

ZABALZA, M. A. O ensino universitário: seu cenário e seus protagonistas. Porto Alegre: ARTMED, 2004.

Recebido em: 14/3/2018.

Aprovado em: 31/5/2019.

Publicado em: 21/12/2019.

Endereço para correspondência:

Andressa Wiebusch

Rua São Simão, 99, apto 1002 - Bairro Bom Jesus

91420-560, Porto Alegre, RS, Brasil

Fernanda Fátima Cofferri

Universidade Federal de Ciências da Saúde de Porto Alegre

Rua Sarmento Leite, 246, sala 502

90030-030, Porto Alegre, RS, Brasil

Gionara Tauchen

Universidade Federal do Rio Grande Av. Itália, Km 8 - Campus Carreiros 96203-900, Rio Grande, RS, Brasil

\section{Autoras:}

ANDRESSA WIEBUSCH

Doutoranda em Educação na Pontifícia Universidade Católica do Rio Grande do Sul (PUCRS), Porto Alegre, RS, Brasil. Professora tutora no Curso de Pedagogia Ead na Universidade Federal de Santa Maria (UFSM). Santa Maria, RS, Brasil.

Orcid: https://orcid.org/0000-0001-6365-2645

E-mail: andressagpfope@gmail.com

FERNANDa Fátima CofFERri

Doutoranda em Educação na Pontifícia Universidade Católica do Rio Grande do Sul (PUCRS), Porto Alegre, RS, Brasil. Pedagoga na Universidade Aberta do SUS na Universidade Federal de Ciências da Saúde de Porto Alegre (UNA-SUS/UFCSPA). Orcid: https://orcid.org/0000-0001-6745-4099

E-mail: fernandacofferri@hotmail.com

GIONARA TAUCHEN

Doutora em Educação na Pontifícia Universidade Católica do Rio Grande do Sul (PUCRS), Porto Alegre, RS, Brasil. Professora associada da Universidade Federal do Rio Grande (FURG), Rio Grande, RS, Brasil.

Orcid: http://orcid.org/0000-0002-3952-0017

E-mail: giotauchen@gmail.com 